\title{
Successful Electroconvulsive Therapy for a 74-year-old Female with Major Depressive Disorder and Tardive Tremor: A Case Report and Literature Review
}

\author{
Jia-Yin Yeh ${ }^{1}$, Nien-Mu Chiu ${ }^{1}$, Yung-Yee Chang ${ }^{2}$, Pao-Yen Lin ${ }^{1}$, Yu Lee ${ }^{1}$ \\ Departments of ${ }^{1}$ Psychiatry and ${ }^{2}$ Neurology, Kaohsiung Chang Gung Memorial Hospital, Chang Gung University College of Medicine, \\ Kaohsiung, Taiwan
}

\begin{abstract}
Tardive tremor is an infrequently form of tardive syndrome that is developed from prolonged treatment with dopamine receptor blocking agents. This condition presents as a prominent tremor that may cause significant distress but currently lacks effective treatment. Electroconvulsive therapy (ECT) has been applied to treat tardive syndrome. In this study, we report a 74-year-old female patient with major depressive disorder, whose tardive tremor and depressive symptoms showed remarkable improvement after receiving 10 sessions of ECT treatment.
\end{abstract}

KEY WORDS: Depression; Electroconvulsive therapy; Tremor.

\section{INTRODUCTION}

Tardive syndrome (TS) is a movement disorder that presents with abnormal, involuntary movement after taking dopamine receptor blocking agents for over three months [1]. Tardive tremor (TT) is one of subtypes of TS that was infrequently documented [2]. Patients with TT have a high-amplitude, 4 to $8 \mathrm{~Hz}$ rest and postural tremors after being chronically treated with dopamine receptor blocking agents [3]. Electroconvulsive therapy (ECT) has been applied to treat TS in the past [1]. However, to the best of our knowledge, no studies have mentioned the improvement of TT after using ECT. In this study, we present a patient with major depressive disorder whose TT

Received: December 11, 2018 / Revised: February 22, 2019

Accepted: March 17, 2019

Address for correspondence: Pao-Yen Lin

Department of Psychiatry, Kaohsiung Chang Gung Memorial

Hospital, Chang Gung University College of Medicine, 123 Dapi

Road, Niaosong District, Kaohsiung City 833, Taiwan

E-mail: paoyenlin@gmail.com

ORCID: https://orcid.org/0000-0002-1394-4567

Yu Lee

Department of Psychiatry, Kaohsiung Chang Gung Memorial

Hospital, Chang Gung University College of Medicine, 123 Dapi

Road, Niaosong District, Kaohsiung City 833, Taiwan

E-mail: leeyu722@ms14.hinet.net

ORCID: https://orcid.org/0000-0001-7322-8936 showed remarkable improvement after receiving ECT treatment.

\section{CASE}

A 74-year-old female has been treated for major depressive disorder that manifested with depressed mood, loss of interest, fatigue, psychomotor retardation, insomnia, poor appetite, negative thoughts, and suicidal ideation since the age of 59 years in 2002. From 2002 to August 2016, her physicians have treated her with several antidepressants, including paroxetine (20 mg/day), venlafaxine (300 mg/day), duloxetine (90 mg/day), escitalopram (20 mg/day), mirtazapine (45 mg/day), agomelatine (50 mg/day), and bupropion (450 mg/day). In this period, her pharmacological treatments have even been augmented with several antipsychotics and other agents, including quetiapine (50 mg/day), aripiprazole (5 mg/day), lithium carbonate $(600 \mathrm{mg} /$ day), and thyroxine sodium (0.1 mg/day). We did not observe any extrapyramidal symptom. And her depressive symptoms were unremitted. In September 2016, she began to receive treatment of mirtazapine $30 \mathrm{mg} /$ day and aripiprazole $5 \mathrm{mg} /$ day. Three months later, tremors over the mandible, lips, tongue, and both hands were detected. No vivid bradykinesia, rigidity

(ㄷ) This is an Open-Access article distributed under the terms of the Creative Commons Attribution Non-Commercial License (http://creativecommons.org/licenses/by-nc/4.0) which permits unrestricted non-commercial use, distribution, and reproduction in any medium, provided the original work is properly cited. 
of limbs, or loss of balance was observed. To relieve the involuntary movement, we changed her medication to quetiapine $25 \mathrm{mg} /$ day, bupropion $150 \mathrm{mg} /$ day, and agomelatine $25 \mathrm{mg} /$ day but observed no improvement. Then, we discontinued all antidepressants and antipsychotics in January 2017. Nevertheless, the tremor symptoms did not improve, and her depressive symptoms were worsened. Her routine blood tests, electrolytes, renal and hepatic functions, thyroid and cortisol hormones, homocysteine, rapid plasma reagin test, autoimmune disorder-related blood examinations, and brain magnetic resonance imaging all revealed no significant abnormalities. The tremography reported a $6 \mathrm{~Hz}$ postural tremor in both hands. We prescribed piracetam 2,400 mg/day, vitamin B6 400 $\mathrm{mg} /$ day, and propranolol $10 \mathrm{mg} /$ day, but the movement symptoms did not improve.

In March 2017, the patient was hospitalized with aggravated depressed mood, hopelessness, and helplessness. A course of ECT was administered due to her severe depressive and distressing tremor symptoms. Intravenous thiamylal sodium 90 to $210 \mathrm{mg}$ was used for the anesthesia. The patient received bitemporal ECT by a Thymatron ${ }^{\circledR}$ system IV machine (Somatics, LLC., Venice, FL, USA) every other day. According to system IV instruction manual, we selected the preset LOW 0.5 program (fixed $0.5 \mathrm{~ms}$ pulsewidth, varies frequency to maximize duration) with a pulse width of 0.5 milliseconds, a frequency of $60 \mathrm{~Hz}$, a duration of 2 seconds, and a current of $0.9 \mathrm{~mA}$ because it provided a broadly effective stimulus that was in the physiological range for most patients. To avoid excessive initial treatment stimuli [4], we did not use most applicable "half-age method" for the bilateral ECT (set PERCENT ENERGY dial to approximately one-half the patient's age, e.g., 35\% for a 70-year-old patient) [5]. We used simple and practical "stimulus titration method" for bitemporal ECT with an initial setting of "PERCENT ENERGY dial" at 10\% ENERGY, followed by re-stimulations at 5\% ENERGY increments until a seizure occurs. If no seizure activity results, the PERCENT ENERGY setting should be increased step by step to $100 \%$ and the patient re-stimulated within 30 to 60 seconds to maximize the likelihood of obtaining a therapeutically satisfactory seizure at the first treatment session. Once the seizure threshold is determined for a specific PERCENT ENERGY setting, the subsequent treatments should be administered at recommended doses approximately 2 times this threshold (e.g., 20\% ENERGY for a patient with 10\% ENERGY seizure threshold). According to motor activity measurement, her seizure duration ranged from 25 to 35 seconds.

Upon completing 10 ECT sessions, both the TT and the depressive symptoms showed significant improvement. The patient's scores on the Extrapyramidal Symptoms Rating Scale decreased from 31 to 15 and from 22 to 10 on the Hamilton Depression Rating Scale-17 items. Retrograde amnesia occurred, but it was temporary and related to the period of impairment immediately following ECT, thus we considered it was the adverse effect of ECT. She was discharged after one month of hospitalization. The tremor symptoms did not recur in the six months after discontinuing all antidepressants and antipsychotics.

This study was approved by the Human Research Ethics Committee of Chang Gung Memorial Hospital (2018 00084B0), and the informed consent was obtained from the subject.

\section{DISCUSSION}

TT was first described by Stacy and Jankovic [2]. This symptom has been reported in less than $3 \%$ of neuroleptic-treated patients [6]. The underlying mechanism of TT is still unknown. One possible explanation is dopamine receptor upregulation in the basal ganglia caused by therapy with chronic dopamine receptor blocking agents, which may also cause disinhibition of the brain stem and cerebellar or thalamic oscillators, and is ultimately expressed as tremors [2].

Few effective treatment options are available for TT. Some studies reported that tetrabenazine may be a possible treatment option $[2,7]$. However, tetrabenazine is known to have a risk of depression in high doses. Furthermore, its tolerability is also problematic, primarily due to its side effects [7].

In our case, the patient exhibited prominent tremors over the mandible, lips, tongue, and $6 \mathrm{~Hz}$ postural tremors on both hands after having undergone prolonged treatment with dopamine receptor blocking agents. The symptoms persisted even after these drugs were discontinued. We were able to rule out tardive parkinsonism as we observed no vivid bradykinesia, rigidity of limbs, or loss of balance; tremor was the only symptom. A diag- 


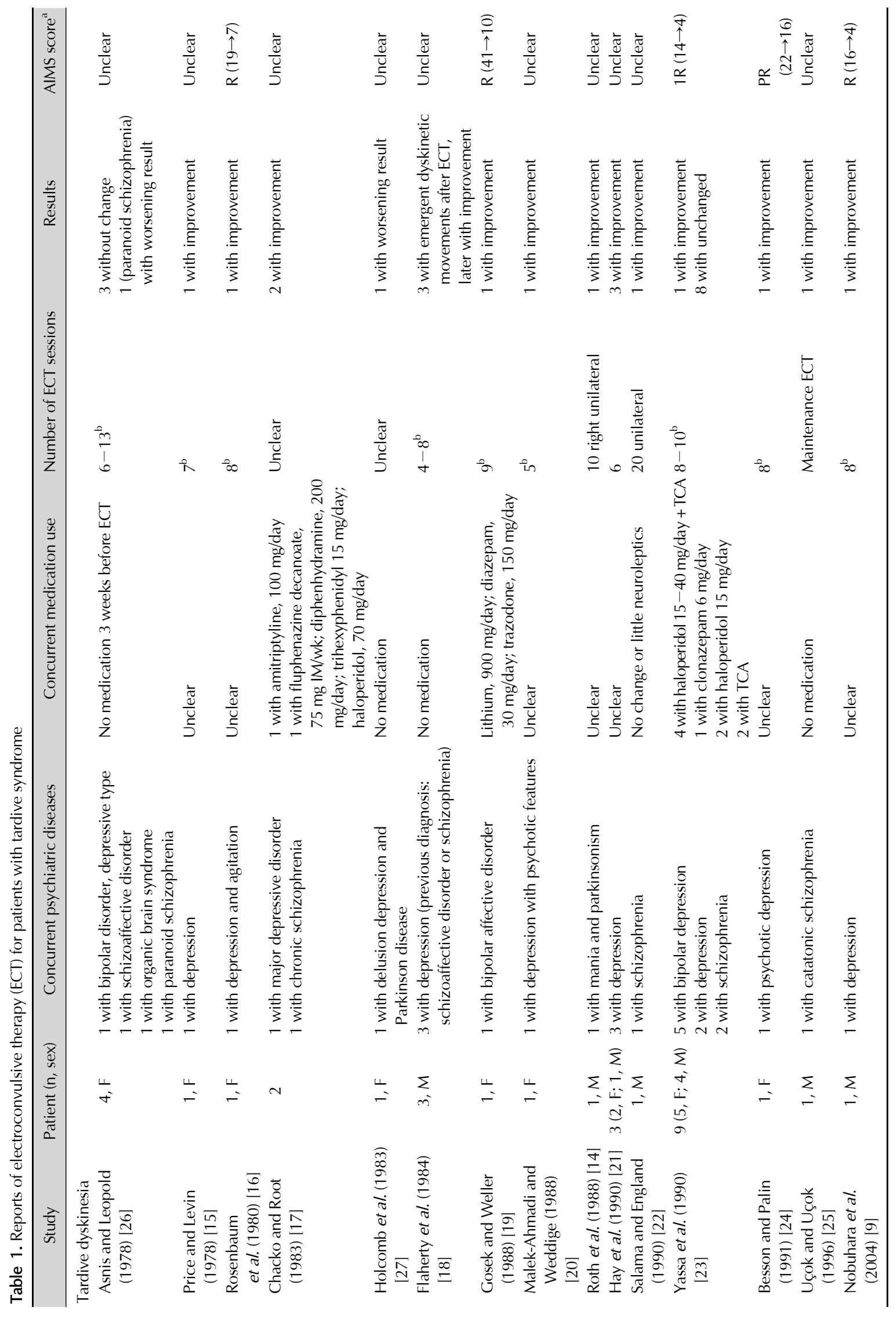




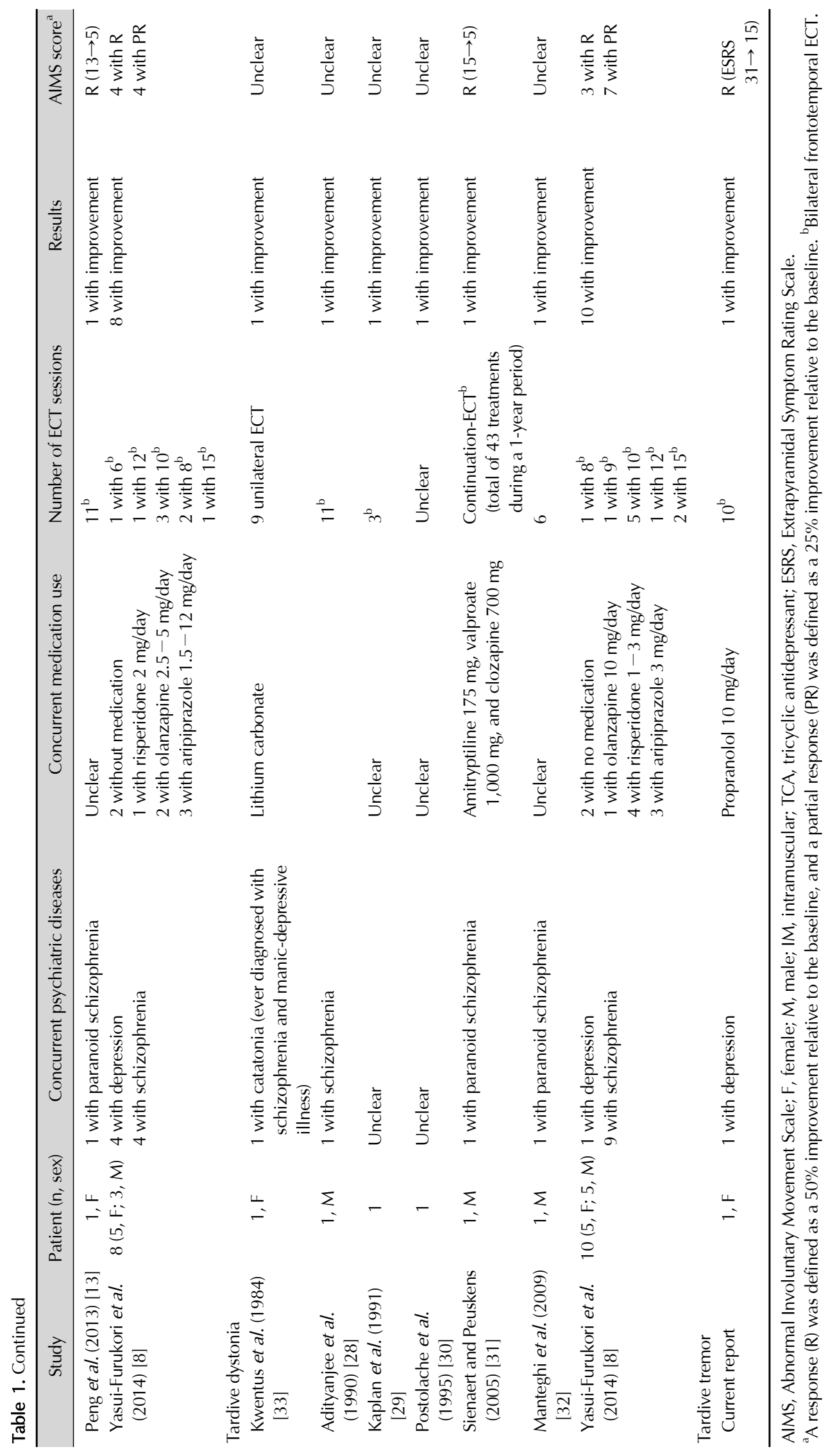


nosis of TT was determined after excluding other possible organic etiologies, e.g. infections, stroke, electrolyte imbalance, thyroid dysfunction, and structural brain lesion. After ECT without taking any antidepressant or antipsychotic medications, she showed marked improvement in both depression and TT symptoms. This result suggests that ECT is a treatment option with satisfactory efficacy for TT patients.

ECT has been reported to be a treatment option for tardive dystonia and tardive dyskinesia with mild to moderate efficacy [8]. Several studies have indicated that it has success in relieving both extrapyramidal symptoms and depressive features of certain patients suffering from concurrent Parkinsonism and depression [9-12]. Currently, no literature has addressed using ECT as a treatment for TT. The possible mechanism associated with ECT in tardive dyskinesia was that ECT may increase striatal GABA concentrations and prevent supersensitization of postsynaptic dopamine receptors, which then allows it to improve dyskinetic symptoms [13]. This effect may also explain its efficacy in resolving TT symptoms.

Here, we review the literatures that documented about the patients with TS, including tardive dyskinesia, tardive dystonia, and tardive tremor, treated by ECT (Table 1). There are 57 patients recruited. Among 40 patients with tardive dyskinesia, after ECT, 27 of the patients had improvement [6,8,9,14-25], 11 patients remained no change $[23,26]$ and 2 patients presented worsening symptoms $[26,27]$. Among 16 patients with tardive dystonia, all of them showed improvement after ECT [8,28-33]. As for TT, our case was the only report and presented with improvement after ECT. Overall, about three fourths of the patients with TS showed improvement after treated with ECT.

However, the influence from the confounding effects of psychiatric diagnosis, concurrent physical illness, previous medications, and the setting and number of sessions of ECT remains unclear [18]. Besides, the adverse cognitive effect throughout the ECT course is also an important issue. Despite these factors, this result suggests that ECT may offer potential treatment for TS. Further larger-scale studies are warranted to clarify the efficacy.

TT is a rare subtype of TS that can be disabling and may not respond to conventional anti-tremor therapy [2]. The patient in our case showed marked improvement in both depressive symptoms and TT after receiving ECT treatment. This result indicates that ECT is a viable treatment option for patients suffering from both depression and TT.

\section{- Conflicts of Interest}

No potential conflict of interest relevant to this article was reported.

\section{Author Contributions}

Conceptualization: Jia-Yin Yeh, Yu Lee. Original draft: Jia-Yin Yeh. Critical revision: Nien-Mu Chiu, Yung-Yee Chang, Pao-Yen Lin, Yu Lee. Supervision: Pao-Yen Lin, Yu Lee.

\section{ORCID}

Jia-Yin Yeh https://orcid.org/0000-0002-2008-8463

Nien-Mu Chiu https://orcid.org/0000-0002-1839-463X Yung-Yee Chang Pao-Yen Lin Yu Lee https://orcid.org/0000-0001-6840-8537 https://orcid.org/0000-0002-1394-4567 https://orcid.org/0000-0001-7322-8936

\section{REFERENCES}

1. Bhidayasiri R, Fahn S, Weiner WJ, Gronseth GS, Sullivan KL, Zesiewicz TA; American Academy of Neurology. Evidencebased guideline: treatment of tardive syndromes: report of the Guideline Development Subcommittee of the American Academy of Neurology. Neurology 2013;81:463-469.

2. Stacy M, Jankovic J. Tardive tremor. Mov Disord 1992;7:5357.

3. Jankovic J. Tardive syndromes and other drug-induced movement disorders. Clin Neuropharmacol 1995;18:197-214.

4. Tiller JW, Ingram N. Seizure threshold determination for electroconvulsive therapy: stimulus dose titration versus age-based estimations. Aust N Z J Psychiatry 2006;40:188-192.

5. Petrides G, Fink M. The "half-age" stimulation strategy for ECT dosing. Convuls Ther 1996;12:138-146.

6. Lee Y, Lin PY, Chang YY, Chong MY, Cheng AT. Antidepressantinduced tardive syndrome: a retrospective epidemiological study. Pharmacopsychiatry 2013;46:281-285.

7. Kertesz DP, Swartz MV, Tadger S, Plopski I, Barak Y. Tetrabenazine for tardive tremor in elderly adults: a prospective follow-up study. Clin Neuropharmacol 2015;38:2325.

8. Yasui-Furukori N, Kikuchi A, Katagai H, Kaneko S. The effects of electroconvulsive therapy on tardive dystonia or dyskinesia induced by psychotropic medication: a retrospective study. Neuropsychiatr Dis Treat 2014;10:1209-1212.

9. Nobuhara K, Matsuda S, Okugawa G, Tamagaki C, Kinoshita T. Successful electroconvulsive treatment of depression associated with a marked reduction in the symptoms of tardive 
dyskinesia. J ECT 2004;20:262-263.

10. Dysken M, Evans HM, Chan CH, Davis JM. Improvement of depression and parkinsonism during ECT: a case study. Neuropsychobiology 1976;2:81-86.

11. Burke WJ, Peterson J, Rubin EH. Electroconvulsive therapy in the treatment of combined depression and Parkinson's disease. Psychosomatics 1988;29:341-346.

12. Mendis T, Suchowersky O, Lang A, Gauthier S. Management of Parkinson's disease a review of current and new therapies. Can J Neurol Sci 1999;26:89-103.

13. Peng LY, Lee Y, Lin PY. Electroconvulsive therapy for a patient with persistent tardive dyskinesia: a case report and literature review. J ECT 2013;29:e52-e54.

14. Roth SD, Mukherjee S, Sackeim HA. Electroconvulsive therapy in a patient with mania, parkinsonism, and tardive dyskinesia. Convuls Ther 1988;4:92-97.

15. Price TR, Levin R. The effects of electroconvulsive therapy on tardive dyskinesia. Am J Psychiatry 1978;135:991-993.

16. Rosenbaum AH, O'Connor MK, Duane DD, Auger RG. Treatment of tardive dyskinesia in an agitated, depressed patient. Psychosomatics 1980;21:765-766.

17. Chacko RC, Root L. ECT and tardive dyskinesia: two cases and a review. J Clin Psychiatry 1983;44:265-266.

18. Flaherty JA, Naidu J, Dysken M. ECT, emergent dyskinesia, and depression. Am J Psychiatry 1984;141:808-809.

19. Gosek E, Weller RA. Improvement of tardive dyskinesia associated with electroconvulsive therapy. I Nerv Ment Dis 1988;176:120-122.

20. Malek-Ahmadi P, Weddige RL. Tardive dyskinesia and electroconvulsive therapy. Convuls Ther 1988;4:328-331.

21. Hay DP, Hay L, Blackwell B, Spiro HR. ECT and tardive dyskinesia. J Geriatr Psychiatry Neurol 1990;3:106-109.

22. Salama AA, England RD. A case study: schizophrenia and tac- tile hallucinations, treated with electroconvulsive therapy. Can J Psychiatry 1990;35:86-87.

23. Yassa R, Hoffman H, Canakis M. The effect of electroconvulsive therapy on tardive dyskinesia: a prospective study. Convuls Ther 1990;6:194-198.

24. Besson JA, Palin AN. Tardive dyskinesia, depression and ECT. Br J Psychiatry 1991;159:446.

25. Uçok A, Uçok G. Maintenance ECT in a patient with catatonic schizophrenia and tardive dyskinesia. Convuls Ther 1996;12: 108-112.

26. Asnis GM, Leopold MA. A single-blind study of ECT in patients with tardive dyskinesia. Am J Psychiatry 1978;135:1235-1237.

27. Holcomb HH, Sternberg DE, Heninger GR. Effects of electroconvulsive therapy on mood, parkinsonism, and tardive dyskinesia in a depressed patient: ECT and dopamine systems. Biol Psychiatry 1983;18:865-873.

28. Adityanjee, Jayaswal SK, Chan TM, Subramaniam M. Temporary remission of tardive dystonia following electroconvulsive therapy. Br J Psychiatry 1990;156:433-435.

29. Kaplan Z, Benjamin J, Zohar J. Remission of tardive dystonia with ECT. Convuls Ther 1991;7:280-283.

30. Postolache TT, Londono JH, Halem RG, Newmark MD. Electroconvulsive therapy in tardive dystonia. Convuls Ther 1995; 11:275-279.

31. Sienaert P, Peuskens J. Remission of tardive dystonia (blepharospasm) after electroconvulsive therapy in a patient with treatment-refractory schizophrenia. J ECT 2005;21:132-134.

32. Manteghi A, Hojjat SK, Javanbakht A. Remission of tardive dystonia with electroconvulsive therapy. J Clin Psychopharmacol 2009;29:314-315.

33. Kwentus JA, Schulz SC, Hart RP. Tardive dystonia, catatonia, and electroconvulsive therapy. I Nerv Ment Dis 1984;172: 171-173. 